\title{
Disparities in access to and use of HIV- related health services in the Netherlands by migrant status and sexual orientation: a cross-sectional study among people recently diagnosed with HIV infection
}

\author{
Janneke P. Bil ${ }^{1,2,3^{*}}$ (D), Freke R. Zuure ${ }^{1,2,3}$, Debora Alvarez-del Arco ${ }^{4}$, Jan M. Prins ${ }^{3}$, Kees Brinkman ${ }^{5}$, Eliane Leyten ${ }^{6}$,
} Ard van Sighem ${ }^{7}$, Fiona Burns ${ }^{8}$ and Maria Prins ${ }^{1,2,3}$

\begin{abstract}
Background: Migrants often face barriers to accessing healthcare. We examined disparities in access to and use of HIV-related health services between migrant and non-migrant people recently diagnosed with HIV living in the Netherlands, taken into account sexual orientation. Also, we examined differences in experiences in living with HIV between these groups.

Methods: We used a questionnaire and clinical data collected between July 2013 and June 2015 among migrant and non-migrant participants of the European cross-sectional aMASE (Advancing Migrant Access to health Services in Europe) study in the Netherlands. Using univariable logistic regression analyses, we compared outcomes on between migrants and non-migrants, stratified by sexual orientation (with non-migrant men having sex with men [MSM] as the reference group).

Results: We included 77 migrant MSM, 115 non-migrant MSM, 21 migrant heterosexual men, 14 non-migrant heterosexual men and 20 migrant women. In univariable analyses, all heterosexual groups were less likely to ever have had an HIV-negative test before their diagnosis and were more likely to be diagnosed late than non-migrant MSM. All migrant groups were more likely to have experienced difficulties accessing general healthcare in the Netherlands and were less likely to have heard of post-exposure prophylaxis than non-migrant MSM. Migrants frequently reported uncertainty about their rights to healthcare and language barriers. Most (93\%) participants visited a healthcare facility in the 2 years before HIV diagnosis but only in $41 \%$ an HIV test was discussed during that visit (no statistical difference between groups). Migrant heterosexuals were more likely to have missed appointments at their HIV clinic due to the travel costs than non-migrant MSM. Migrant MSM and women were more likely to have experienced HIV discrimination in the Netherlands than non-migrant MSM.
\end{abstract}

(Continued on next page)

\footnotetext{
*Correspondence: jbil@ggd.amsterdam.nl

'Department of Infectious Diseases Research and Prevention, Public Health

Service of Amsterdam, Amsterdam, the Netherlands

${ }^{2}$ Amsterdam Infection and Immunity Institute (AI\&II), Amsterdam UMC

(location AMC), University of Amsterdam, Amsterdam, the Netherlands

Full list of author information is available at the end of the article
}

(c) The Author(s). 2019 Open Access This article is distributed under the terms of the Creative Commons Attribution 4.0 International License (http://creativecommons.org/licenses/by/4.0/), which permits unrestricted use, distribution, and reproduction in any medium, provided you give appropriate credit to the original author(s) and the source, provide a link to the Creative Commons license, and indicate if changes were made. The Creative Commons Public Domain Dedication waiver (http://creativecommons.org/publicdomain/zero/1.0/) applies to the data made available in this article, unless otherwise stated. 
(Continued from previous page)

Conclusion: Disparities in access to and use of HIV-related health services and experiences exist by migrant status but also by sexual orientation. Our data suggests heterosexual men and women may particularly benefit from improved access to HIV testing (e.g., through provider-initiated testing), while migrant MSM may benefit from improved access to HIV prevention interventions (e.g., pre-exposure prophylaxis).

Keywords: Migrants, HIV/AIDS, Health services, Epidemiology

\section{Background}

Migrants represent a significant group in the HIV epidemic across Europe, including in the Netherlands [1-3]. An estimated 22,900 people were living with HIV in the Netherlands in 2017, with 89\% diagnosed and linked to care, $92 \%$ of those in care were on combination antiretroviral therapy (cART) and of those on ART 95\% were virally supressed [4]. Almost half (43\%) of all HIV-positive people in care in the Netherlands in 2017 were born outside of the Netherlands [4] and data suggest that migrants are doing less well in the cascade of care. HIV-positive people originating from South-East Asia, sub-Saharan Africa, Surinam, the Caribbean or Latin America were more likely to enter clinical care with late-stage infection (clinical AIDS event or a CD4-count $<350$ cells $/ \mathrm{mm}^{3}$ ) or an advanced HIV infection (AIDS or CD4-count $<200$ cells $/ \mathrm{mm}^{3}$ ) than those of Dutch origin [5]. In the Netherlands, migrants are also more likely to have higher rates of lost to follow-up from HIV care [6], a longer time to virological suppression after combination antiretroviral therapy (cART) initiation, and higher risk of treatment failure [4] than those of Dutch origin. These data are in line with findings across the European Union/Economic Area [3] and suggest migrants face barriers in accessing and utilizing HIV health services. Hence, we need to better understand the specific barriers migrants face. Such data guide the development of strategies aimed at improving HIV prevention measures as well as optimising individual and public health outcomes.

The advancing Migrant Access to health Services in Europe (aMASE) study was set up to examine access to and use of HIV-related health services and identify structural, cultural and financial barriers to HIV prevention, diagnosis and treatment among several migrant groups living in Europe [7]. Results of the aMASE study suggest opportunities for HIV testing and prevention are still being missed among migrants living in Europe [810]. However, the extent to which this differs between migrants and non-migrants and according to their sexual orientation is not well known. Therefore, this study aims to examine differences in access to and use of HIVrelated health services between migrants and nonmigrants recently diagnosed in the Netherlands, taken into account their sexual orientation. In addition, we examined differences in experiences in living with HIV between these groups.

\section{Methods}

\section{Study design and procedures}

A cross-sectional study was conducted among migrant and non-migrant individuals living with HIV in the Netherlands. Migrants were included in the clinic survey of the aMASE study, as described in detail elsewhere [7]. In summary, the aMASE study was conducted between July 2013 and June 2015 in nine European countries. Migrants were included if they were diagnosed with HIV within 5 years of recruitment, aged $>18$ years, foreign-born and resident in the country of recruitment for $\geq 6$ months, and able to complete, either alone or supported, a computer-assisted self or personal interview in any one of the 15 languages available. For the present study, we used data collected at all participating HIV outpatient treatment clinics in the Netherlands (Amsterdam UMC [location AMC], OLVG in Amsterdam and Haaglanden Medisch Centrum, in The Hague). In addition to the aMASE data collection among migrants, in the Netherlands all non-migrants (i.e., those born in the Netherlands) who attended any of the three HIV outpatient treatment clinics during the same study period and were diagnosed with HIV within 5 years and aged $\geq 18$ years were also asked to participate.

Participants completed a questionnaire on HIV-related services (which included access to HIV testing and healthcare pre-diagnosis and access to treatment and ongoing care after HIV diagnosis) and experiences. Clinical data were obtained from the national ATHENA (AIDS Therapy Evaluation in the Netherlands) HIV cohort database [4]. For people who declined to participate, we collected data on age, country of birth, sexual orientation and reason for decline.

\section{Variables}

\section{Socio-demographic characteristics and migration history}

Characteristics included self-reported sexual orientation, self-defined ethnicity, educational level, current work status, income level, age, household hunger in the past 4 weeks and attending religious services. Migration history included years since migration, age at migration, region of birth and immigration status.

\section{Access to HIV testing and healthcare pre-diagnosis}

We measured factors related to HIV diagnosis, HIV testing behaviour, access to care and awareness of post- 
exposure prophylaxis (PEP). Factors related to HIV diagnosis included: age at HIV diagnosis, years since HIV diagnosis, location of HIV diagnosis, reason for HIV test, CD4 count and late stage HIV infection at HIV diagnosis. Among migrants we also collected data on the years between migration to the Netherlands and HIV diagnosis, country of HIV diagnosis and country of previous HIV negative test. Factors related to HIV test behaviour included: ever had an HIV test before HIV diagnosis and years between previous negative HIV test and HIV diagnosis. Variables measuring access to care included registration at a general practitioner (GP) in the Netherlands (GPs are the first point of access to healthcare in the Netherlands), healthcare usage in the Netherlands in the 2 years before HIV diagnosis and experienced difficulties accessing healthcare in the Netherlands. Among those who used healthcare in the Netherlands, we asked which healthcare professionals were visited and whether or not an HIV test was discussed during these visits.

\section{Access to treatment and ongoing care}

We measured use of cART, time between HIV diagnosis and starting cART, self-reported cART adherence and self-reported difficulty to take HIV medication on a regular basis. Furthermore, participants were asked if they ever missed an appointment at the HIV clinic due to the travel costs.

\section{Experiences in living with HIV}

Participants were asked if they had disclosed their HIV status to their steady partner or to friends and family, if they received HIV support through any non-governmental organizations (NGOs), and if they ever felt discriminated in the Netherlands because of their HIV status, ethnicity, race or origin, or sexuality.

\section{Statistical analyses}

As previous studies have shown outcomes are influenced by sexual orientation $[8,9]$, participants were grouped into: migrant MSM, non-migrant MSM, migrant heterosexual men, non-migrant heterosexual men, migrant women and non-migrant women. Socio-demographic characteristics and non-dichotomous outcomes were compared between groups using chi-square tests and Fisher's exact tests for categorical variables and one-way ANOVA (normally distributed) and Kruskal Wallis tests (not normally distributed) for continuous variables. Dichotomous outcomes related to access to HIV prevention, testing, care pre-diagnosis, treatment, ongoing care and experiences in living with HIV were used as separate end-points. The univariable odds ratios (ORs) were calculated using logistic regression or penalized logistic regression in a table with a zero cell count [11].
In additional analyses, we adjusted outcomes for participants' age by constructing multivariable models as age is a potential confounder. We also compared all outcomes by region of birth in MSM only, due to the low numbers of migrant heterosexual men and women.

In the analyses, participants with unknown or missing data were excluded. Analyses were performed using STATA Intercooled 13.1 (STATA Corporation, College Station, Texas, USA). A $p$ value of $<0.05$ was considered statistically significant.

\section{Results}

Of 417 invited HIV-positive patients, 60\% $(n=252)$ participated. The response rate was lower among migrants from Latin America/Caribbean and women and heterosexual men than non-migrants and MSM, respectively. Also, participants recruited at the Amsterdam UMC were less likely to participate than those recruited elsewhere.

In total 247 participants were included in the analyses (Table 1): 77 migrant MSM, 115 non-migrant MSM, 21 migrant heterosexual men, 14 non-migrant heterosexual men and 20 migrant women. Five non-migrant women were excluded from the analyses because of their low number. Groups differed with regard to variables reflecting socio-economic status (all $p$-values $<0.01$ ), current age $(p=0.002)$, age at migration $(p=0.003)$, self-defined ethnicity $(p<0.001)$, immigration status $(p<0.001)$, attendance of religious services $(p<0.001)$ and recruitment site $(p=0.012)$ (Table 1$)$. There was a difference in region of birth between MSM and heterosexual migrants $(p<0.001)$; with $40 \%$ of the MSM migrants originating from Europe and more than half of the heterosexual migrants originate from sub-Saharan Africa.

\section{Access to HIV testing and healthcare pre-diagnosis}

The median age at HIV diagnosis was 39 years (IQR 31-47) and median time since HIV diagnosis was 2 years (IQR 1-4) (Table 2). Migrants were a median of 8 years (IQR 2-21) in the Netherlands before HIV diagnosis.

While MSM were most frequently diagnosed at a sexual health or HIV testing clinic and most commonly tested for HIV because it was part of a routine health check-up, most heterosexuals men and women (both migrants and non-migrants) were diagnosed in a hospital and stated a doctor advised the HIV test due to health problems.

Overall, $78 \%$ had a previous negative HIV test before HIV diagnosis and $42 \%$ were diagnosed with a late-stage HIV infection. Most (93\%) participants visited a healthcare facility in the 2 years prior to diagnosis, with $41 \%$ reporting that HIV testing was discussed (Table 2). Most participants who used a healthcare facility visited a GP 


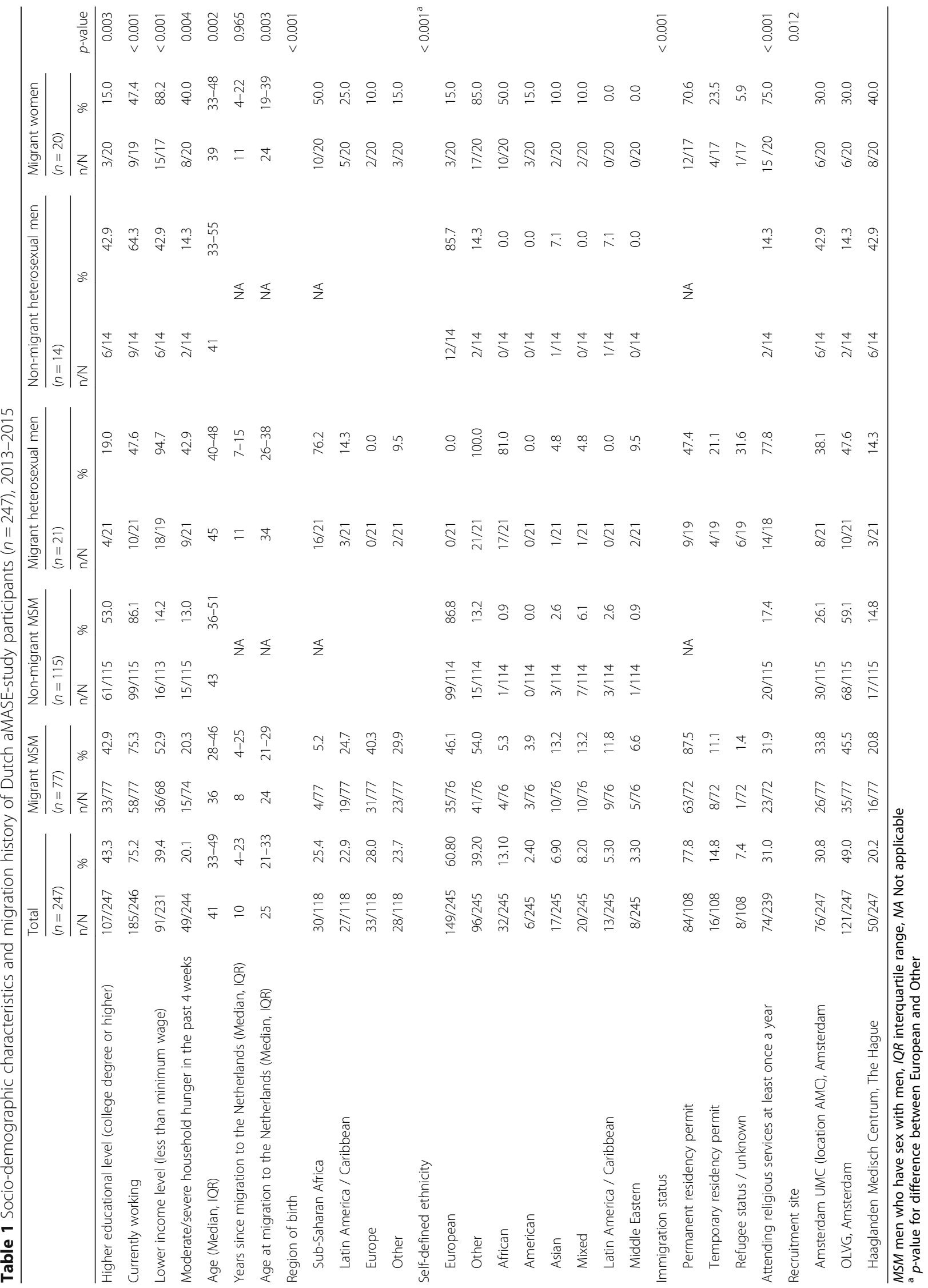


Table 2 Access to HIV testing and healthcare pre-diagnosis among Dutch aMASE-study participants $(n=247), 2013-2015$

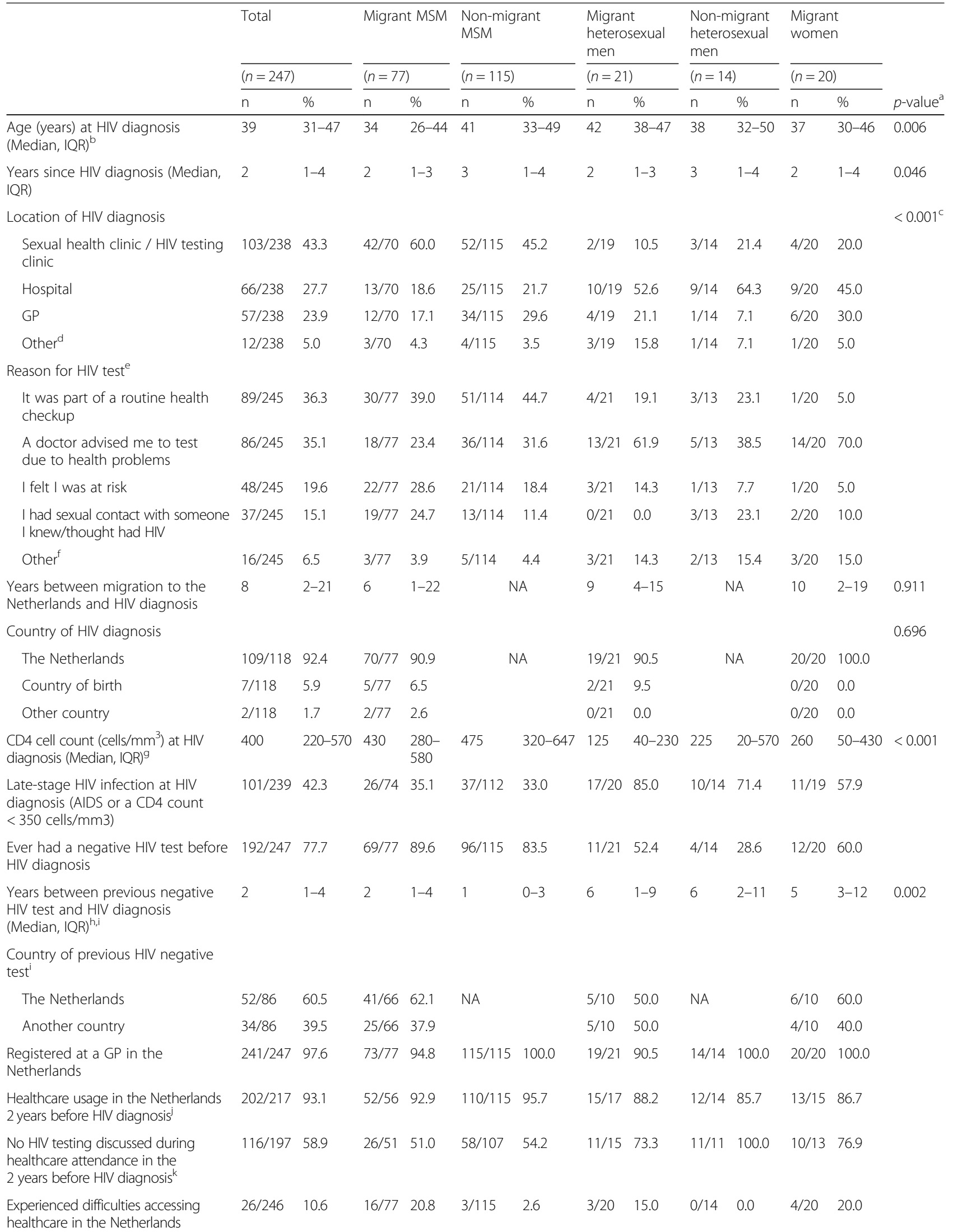


Table 2 Access to HIV testing and healthcare pre-diagnosis among Dutch aMASE-study participants $(n=247), 2013-2015$ (Continued)

\begin{tabular}{|c|c|c|c|c|c|}
\hline Total & Migrant MSM & $\begin{array}{l}\text { Non-migrant } \\
\text { MSM }\end{array}$ & $\begin{array}{l}\text { Migrant } \\
\text { heterosexual } \\
\text { men }\end{array}$ & $\begin{array}{l}\text { Non-migrant } \\
\text { heterosexual } \\
\text { men }\end{array}$ & $\begin{array}{l}\text { Migrant } \\
\text { women }\end{array}$ \\
\hline$(n=247)$ & $(n=77)$ & $(n=115)$ & $(n=21)$ & $(n=14)$ & $(n=20)$ \\
\hline$\%$ & $\%$ & $\%$ & $\%$ & $\%$ & $\%$ \\
\hline
\end{tabular}

Type of difficulties experienced in accessing

healthcare in the Netherlands ${ }^{\mathrm{e}, \mathrm{l}}$

\begin{tabular}{|c|c|c|c|c|c|c|c|c|c|c|c|c|}
\hline $\begin{array}{l}\text { I am still unsure of my rights } \\
\text { to access healthcare }\end{array}$ & $10 / 26$ & 38.5 & $5 / 16$ & 31.3 & $0 / 3$ & 0.0 & $3 / 3$ & 100.0 & $0 / 0$ & 0.0 & $2 / 4$ & 50.0 \\
\hline $\begin{array}{l}\text { Clinic opening hours are } \\
\text { inconvenient }\end{array}$ & $5 / 26$ & 19.2 & $4 / 16$ & 25.0 & $1 / 3$ & 33.3 & $0 / 3$ & 0.0 & $0 / 0$ & 0.0 & $0 / 4$ & 0.0 \\
\hline $\begin{array}{l}\text { There are long waiting times } \\
\text { for an appointment }\end{array}$ & $6 / 26$ & 23.1 & $4 / 16$ & 25.0 & $1 / 3$ & 33.3 & $0 / 3$ & 0.0 & $0 / 0$ & 0.0 & $1 / 4$ & 25.0 \\
\hline $\begin{array}{l}\text { I have difficulty communicating } \\
\text { with staff because of language } \\
\text { differences }\end{array}$ & $8 / 26$ & 30.8 & $3 / 16$ & 18.8 & $0 / 3$ & 0.0 & $2 / 3$ & 66.7 & $0 / 0$ & 0.0 & $3 / 4$ & 75.0 \\
\hline Other & $13 / 26$ & 50.0 & $8 / 16$ & 50.0 & $3 / 3$ & 100.0 & $1 / 3$ & 33.3 & $0 / 0$ & 0.0 & $1 / 4$ & 25.0 \\
\hline r heard of post-exposure & $162 / 245$ & 66.1 & $46 / 77$ & 59.7 & $101 / 113$ & 89.4 & $3 / 21$ & 14.3 & $8 / 14$ & 57.1 & $4 / 20$ & 20.0 \\
\hline
\end{tabular}
prophylaxis (PEP)

MSM men who have sex with men, IQR interquartile range, GP General Practitioner

a only $p$-values are presented for variables not included in Fig. 2

${ }^{b} 3$ missings

c $p$-value calculated without the other category

${ }^{d}$ Other includes: antenatal care $(n=3)$, refugee center $(n=3)$, fertility clinic $(n=1)$, dentist $(n=1)$, self-test $(n=1)$, medical examination $(n=1)$, private clinic $(n=1)$, unknown $(n=1)$

${ }^{\mathrm{e}}$ Total number and percentage exceeds $100 \%$ because more than one answer could be given

${ }^{f}$ Other reasons are for example: pregnancy, test done without permission of participant, relationship, sexual assault

${ }^{9} 8$ missings

h 56 missings

' Only participants were included who had a previous negative HIV test before diagnosis

j Only participants were included who lived in the Netherlands for 2 years or more and who were diagnosed with HIV in the Netherlands

${ }^{k}$ Only participants were included who lived in the Netherlands for 2 years or more, who were diagnosed with HIV in the Netherlands and who had used

healthcare in the Netherlands in the previous 2 years before HIV diagnosis

'Only participants were included who experienced difficulties accessing healthcare in the Netherlands

and/or dentist; $26 \%$ of those who visited a GP, recalled that an HIV test was discussed (Fig. 1). The proportion visiting a GP was lower among migrant groups (range 53-65\%) than among the non-migrant groups (range $74-84 \%)(p=0.009)$.

In univariable analyses (Fig. 2a), having had a previous HIV-negative test was less likely in migrant heterosexual men (OR:0.22, 95\%-CI:0.08-0.58), non-migrant heterosexual men (OR:0.09, 95\%-CI:0.03-0.29) and migrant women (OR:0.30, 95\%-CI:0.11-0.81) than in non-migrant MSM, whereas the difference between migrant (OR:1.65, 95\%-CI: 0.70-3.91) and non-migrant MSM was not statistically significant. Also, among those who had an HIV-negative test, the median time between the previous HIV-negative test and HIV diagnosis was significantly longer among all heterosexual men and women than migrant and nonmigrant MSM ( $p=0.002$, Table 2). Being diagnosed with a late-stage HIV infection was more likely in migrant heterosexual men (OR:11.49, 95\%-CI 3.17-41.69), nonmigrant heterosexual men (OR:5.07, 95\%-CI:1.49-17.24) and migrant women (OR:2.79, 95\%-CI:1.03-7.52) than non-migrant MSM, whereas this did not differ between migrant (OR:1.10, 95\%-CI:0.59-2.04) and non-migrant
MSM. All three migrant groups (MSM [OR:8.62, 95\%-CI: 2.61-28.48], heterosexual men [OR:6.43, 95\%-CI 1.3430.74] and women [OR:8.77, 95\%-CI 1.98-38.97]) were more likely to have experienced difficulties accessing healthcare in the Netherlands than non-migrant MSM. Most frequently reported difficulties accessing healthcare in the Netherlands among migrants were uncertainty regarding their right to access healthcare and language barriers (Table 2). Overall, 66\% had ever heard of PEP. Migrant MSM (OR:0.18, 95\%-CI:0.08-0.37), migrant heterosexual men (OR:0.02, 95\%-CI:0.01-0.08), non-migrant heterosexual men (OR:0.16, 95\%-CI:0.05-0.53) and migrant women (OR:0.03, 95\%-CI:0.01-0.10) were less likely to have heard of PEP than non-migrant MSM. Healthcare usage in the 2 years before HIV diagnosis and the proportion in which an HIV test was discussed during healthcare attendance did not differ significantly between groups.

Comparing outcomes by region of birth and restricting the analyses to MSM, MSM born in sub-Saharan Africa (OR:12.44, 95\%-CI:0.98-157.33), another country in Europe (OR:8.96, 95\%-CI:2.10-38.28) or in another region (OR: 19.91, 95\%-CI:4.75-83.38) were more likely to have 


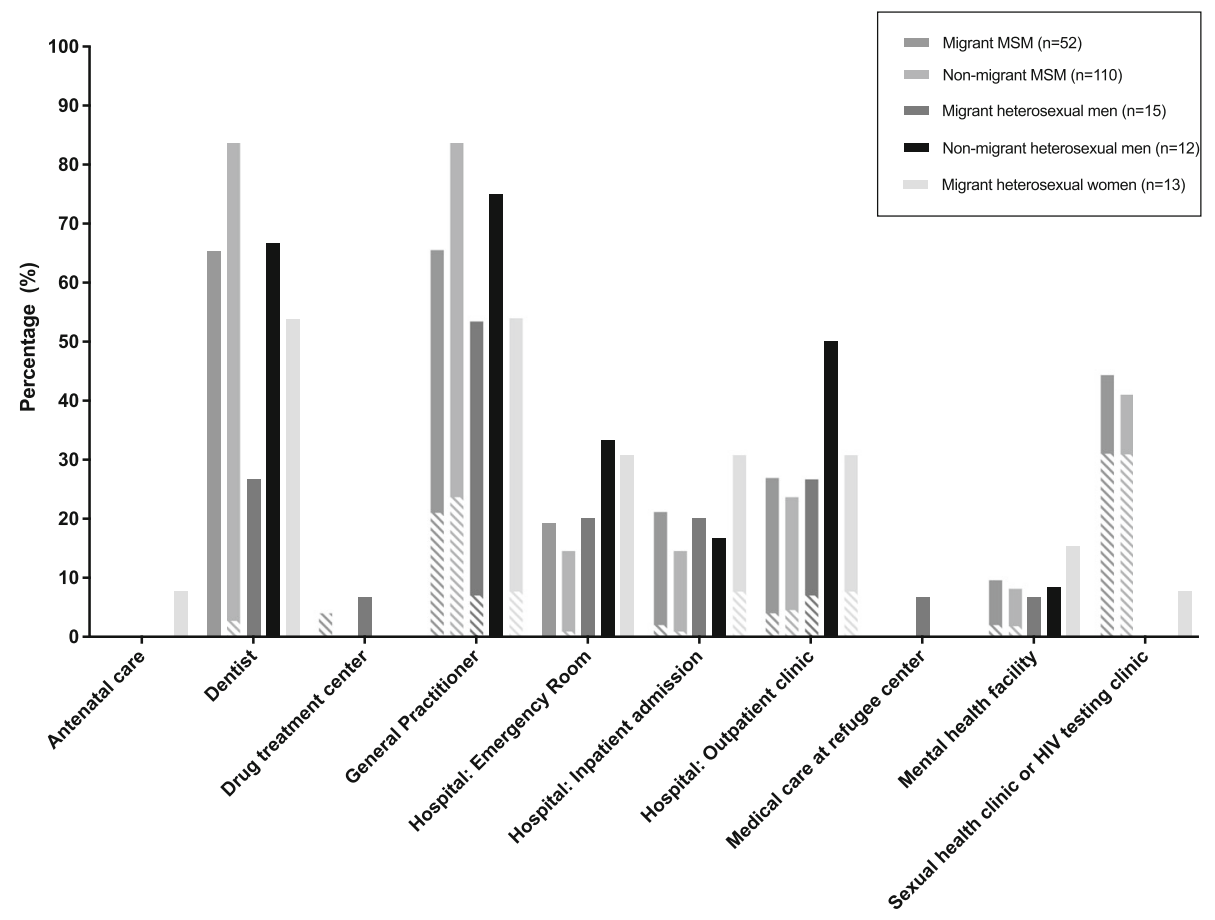

Fig. 1 Healthcare attendance in the 2 years before HIV diagnosis and the proportion in which HIV testing was discussed among Dutch aMASEstudy participants, 2013-2015. Note: dashed lines represent the proportion of cases in which an HIV test was discussed during healthcare attendance. MSM: Men who have sex with men

difficulties accessing healthcare in the Netherlands than non-migrant MSM. Also, MSM born in subSaharan Africa (OR:0.12, 95\%-CI:0.02-0.92), Latin America/Caribbean (OR:0.13, 95\%-CI:0.04-0.39), another country in Europe (OR:0.29, 95\%-CI:0.11-0.77) or in another region (OR:0.13, 95\%-CI:0.05-0.36) were less likely to have heard of PEP than non-migrant MSM. No significant differences were found in the other outcomes on access to HIV testing and healthcare pre-diagnosis between region of birth among MSM.

\section{Access to treatment and ongoing HIV care}

Overall, $86 \%$ of participants reported they were on cART, median time between HIV diagnosis and starting cART was 6 weeks (IQR 3-43). Almost all (98\%) reported high cART adherence, $14 \%$ found it difficult to take HIV medication on a regular basis; $4 \%$ missed appointments at their HIV clinic due to the travel costs (Table 3).

In univariable analyses (Fig. 2b), migrant heterosexual men (OR:14.44,95\%-CI:2.00-104.05) and migrant women (OR:15.27,95\%-CI:2.11-110.33) were more likely to have missed appointments at their HIV clinic due to the travel costs than non-migrant MSM. All heterosexual groups were more likely to start cART earlier after their HIV diagnosis than non-migrant and migrant MSM $(p=0.002$, Table 3). No significant differences were found in the other outcomes on access to treatment and ongoing HIV care and there were no significant differences between region of birth among MSM.

\section{Experiences in living with HIV}

Most participants had disclosed their HIV status to their steady partner (94\%) and to friends and family (83\%) and $23 \%$ were in contact with an NGO for HIV support (Table 4). 16\% respondents reported experiencing discrimination because of their HIV status. Among migrants, $43 \%$ reported discrimination in the Netherlands because of their ethnicity, race or country of origin and $46 \%$ of migrant and non-migrant MSM reported discrimination because of their sexuality.

In univariable analyses (Fig. 2c), migrant MSM (OR:3.50, 95\%-CI:1.52-8.03) and migrant women (OR:4.50, 95\%-CI: 1.42-14.29) were more likely to report ever been discriminated in the Netherlands because of their HIV-status than non-migrant MSM. Other outcomes on experiences in living with HIV did not differ significantly between groups.

Comparing outcomes of experiences in living with HIV by region of birth, MSM born in a region other than subSaharan Africa, Latin America/Caribbean or Europe were less likely to be in contact with an NGO for HIV support than non-migrant MSM (OR:0.11, 95\%-CI:0.39-3.13). MSM born in sub-Saharan Africa (OR:3.50, 95\%-CI:0.3336.86), Latin-America/Caribbean (OR:1.97,95\%-CI:0.49- 
A. Access to testing and healthcare pre HIV diagnosis Ever had a negative HIV test before HIV diagnosis ${ }^{* * *}$

Healthcare usage in the Netherlands 2 years before HIV diagnosis ${ }^{a}$

No HIV test discussed during healthcare attendance in the 2 years before HIV diagnosis ${ }^{b}$

Experienced difficulties accessing healthcare in the Netherlands**

Ever heard of PEP ${ }^{* \star *}$

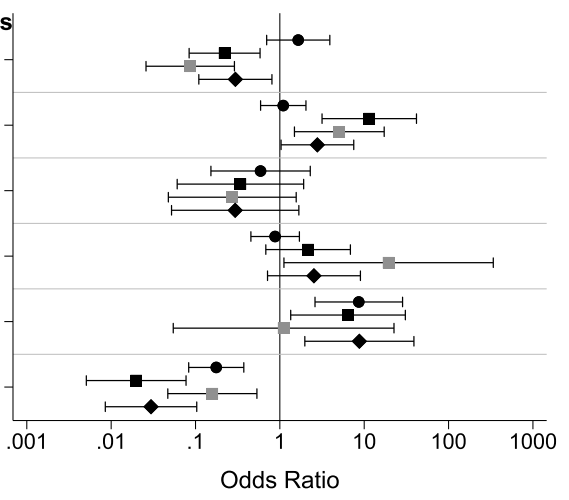

B. Access to treatment and ongoing care

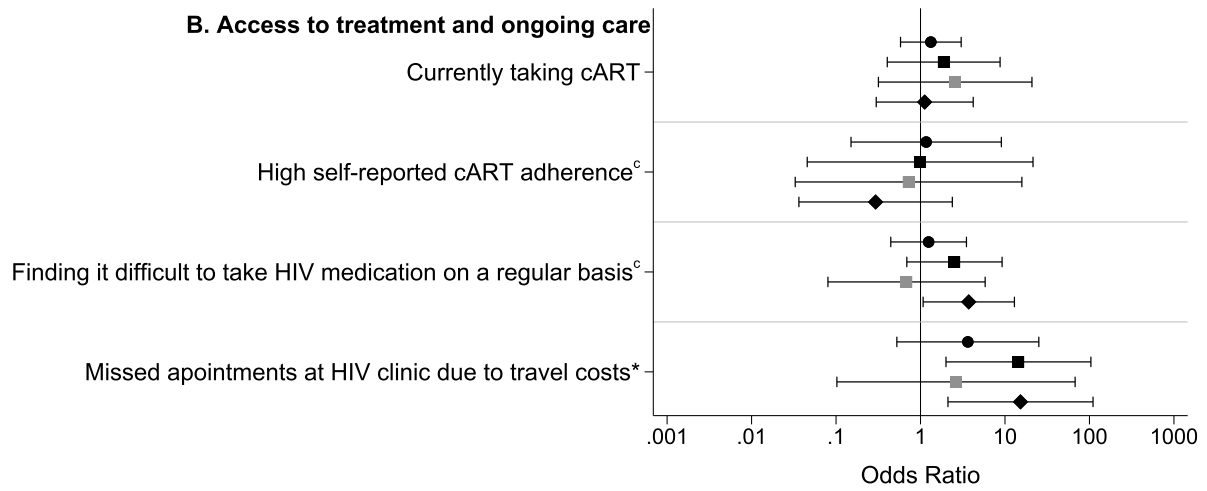

C. Experiences in living with HIV

Disclosure of HIV status to steady partner ${ }^{d}$

Disclosure of HIV status to friends or family

In contact with any NGO's for HIV support

Ever been discriminated in the Netherlands because of HIV status*

Ever been discriminated in the Netherlands because of sexuality ${ }^{e}$

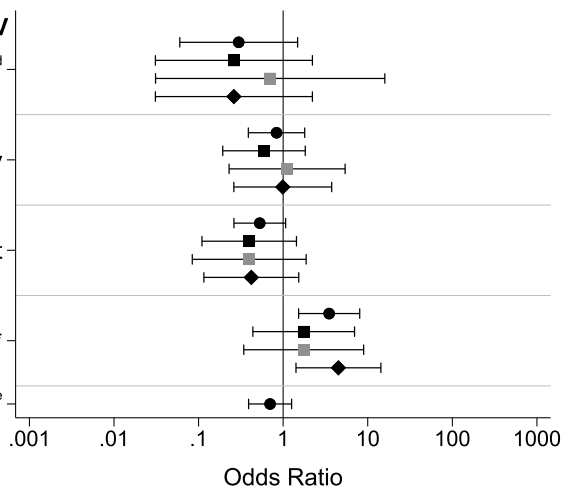

Non-migrant MSM (ref.) • Migrant MSM - Migrant heterosexual men $\quad$ Non-Migrant heterosexual men $\bullet$ Migrant women

Fig. 2 Univariable analyses of the relationship between migrant status and sexual orientation and (a) access to testing and healthcare pre HIV diagnosis, (b) access to treatment and ongoing care and (c) experiences in living with HIV among Dutch aMASE-study participants, $2013-2015$. MSM: men who have sex with men; PEP: post-exposure prophylaxis; CART: combination antiretroviral therapy; NGO: non-governmental organisation. ${ }^{\text {a }}$ Only participants were included who lived in the Netherlands for 2 years or more and who were diagnosed with HIV in the Netherlands. ${ }^{b}$ Only participants were included who lived in the Netherlands for 2 years or more, who were diagnosed with HIV in the Netherlands and who had used healthcare in the Netherlands in the previous 2 years before HIV diagnosis. ${ }^{C}$ Only participants were included who were currently using CART. ${ }^{d}$ Only participants were included who had a steady partner. ${ }^{\text {e }}$ Only MSM were included in this analysis. ${ }^{*} p<0.05$ ${ }^{* *} p<0.01{ }^{* * *} p<0.001$ 
Table 3 Access to treatment and ongoing HIV care among Dutch aMASE-study participants $(n=247), 2013-2015$

\begin{tabular}{|c|c|c|c|c|c|c|c|c|c|c|c|c|c|}
\hline & \multicolumn{2}{|l|}{ Total } & \multicolumn{2}{|c|}{$\begin{array}{l}\text { Migrant } \\
\text { MSM }\end{array}$} & \multicolumn{2}{|c|}{$\begin{array}{l}\text { Non-migrant } \\
\text { MSM }\end{array}$} & \multicolumn{2}{|c|}{$\begin{array}{l}\text { Migrant } \\
\text { heterosexual } \\
\text { men }\end{array}$} & \multirow{2}{*}{\multicolumn{2}{|c|}{$\begin{array}{l}\text { Non-migrant } \\
\text { heterosexual } \\
\text { men } \\
(n=14)\end{array}$}} & \multirow{2}{*}{\multicolumn{2}{|c|}{$\begin{array}{l}\text { Migrant } \\
\text { women } \\
(n=20)\end{array}$}} & \multirow[b]{3}{*}{$p$-value } \\
\hline & \multicolumn{2}{|l|}{$(n=247)$} & \multicolumn{2}{|c|}{$(n=77)$} & \multicolumn{2}{|c|}{$(n=115)$} & \multicolumn{2}{|c|}{$(n=21)$} & & & & & \\
\hline & $n$ & $\%$ & $n$ & $\%$ & $n$ & $\%$ & $n$ & $\%$ & $n$ & $\%$ & $n$ & $\%$ & \\
\hline Currently taking CART & $212 / 247$ & 85.8 & $67 / 77$ & 87.0 & $96 / 115$ & 83.5 & $19 / 21$ & 90.5 & $13 / 14$ & 92.9 & $17 / 20$ & 85.0 & \\
\hline $\begin{array}{l}\text { Weeks between start CART and HIV } \\
\text { diagnosis (Median, IQR) })^{\mathrm{b}, \mathrm{c}}\end{array}$ & 6 & $3-43$ & 9 & $3-31$ & 7 & $4-59$ & 3 & $1-7$ & 3 & $2-7$ & 3 & $2-34$ & 0.002 \\
\hline Reason for no cART use ${ }^{d}$ & & & & & & & & & & & & & \\
\hline My doctor says I do not need them yet & $21 / 35$ & 60.0 & $6 / 10$ & 60.0 & $12 / 19$ & 63.2 & $0 / 2$ & 0.0 & $1 / 1$ & 100.0 & $2 / 3$ & 66.7 & \\
\hline I'm afraid of the side effects & $3 / 35$ & 8.6 & $0 / 10$ & 0.0 & $2 / 19$ & 10.5 & $0 / 2$ & 0.0 & $0 / 1$ & 0.0 & $1 / 3$ & 33.3 & \\
\hline $\begin{array}{l}\text { I'm on a treatment break I agreed with } \\
\text { my doctor }\end{array}$ & $5 / 35$ & 14.3 & $1 / 10$ & 10.0 & $4 / 19$ & 21.1 & $0 / 2$ & 0.0 & $0 / 1$ & 0.0 & $0 / 3$ & 0.0 & \\
\hline I will start soon/today & $8 / 35$ & 22.9 & $3 / 10$ & 30.0 & $3 / 19$ & 15.8 & $2 / 2$ & 100.0 & $0 / 1$ & 0.0 & $0 / 3$ & 0.0 & \\
\hline I am waiting for approval & $1 / 35$ & 2.9 & $0 / 10$ & 0.0 & $1 / 19$ & 5.3 & $0 / 2$ & 0.0 & $0 / 1$ & 0.0 & $0 / 3$ & 0.0 & \\
\hline High self-reported cART adherence ${ }^{b, e}$ & $205 / 209$ & 98.1 & $65 / 66$ & 98.5 & $93 / 95$ & 97.9 & $18 / 18$ & 100.0 & $13 / 13$ & 100.0 & $16 / 17$ & 94.1 & \\
\hline $\begin{array}{l}\text { Finding it difficult to take HIV medication } \\
\text { on a regular basis, } \mathrm{f}\end{array}$ & $27 / 191$ & 14.1 & $7 / 53$ & 13.2 & $10 / 92$ & 10.9 & $4 / 17$ & 23.5 & $1 / 13$ & 7.7 & $5 / 16$ & 31.3 & \\
\hline $\begin{array}{l}\text { Missed appointments at HIV clinic } \\
\text { due to the travel costs }\end{array}$ & $10 / 246$ & 4.1 & $3 / 76$ & 3.9 & $1 / 115$ & 0.9 & $3 / 21$ & 14.3 & $0 / 14$ & 0.0 & $3 / 20$ & 15.0 & \\
\hline
\end{tabular}

MSM men who have sex with men, CART combination antiretroviral therapy, IQR interquartile range

${ }^{a}$ only $p$-values are presented for variables not included in Fig. 2

${ }^{\mathrm{b}}$ Only participants were included who were currently using cART

c 16 missings

${ }^{\mathrm{d}}$ Only participants were included who were not currently using CART. Total number and percentage exceeds $100 \%$ because participants could indicate more than one reason

${ }^{\text {e }}$ Measured on a 4-point Likert scale and dichotomized for analyses whereas the answers strongly agree and agree on the statement "I always follow my doctor's instructions about taking my HIV medication" represent high self-reported cART adherence and strongly disagree and disagree represents low self-reported adherence

${ }^{f}$ Measured on a 4-point Likert scale and dichotomized for analyses whereas the answers strongly agree and agree on the statement "I find it difficult to take my HIV medication on a regular basis" represent finding it difficult to take HIV medication on a regular basis and strongly disagree and disagree represents not finding it difficult to take HIV medication on a regular basis

7.93), another country in Europe (OR:4.50, 95\%-CI:1.6312.42) or another region (OR:3.71, 95\%-CI:1.19-11.52) were more likely to have experienced HIV discrimination in the Netherlands than non-migrant MSM, although this effect was not statistically significant for MSM from subSaharan Africa and Latin-America/Caribbean. Other outcomes on experiences in living with HIV did not differ significantly between region of birth among MSM.

When adjusting for age, outcomes on access to testing and healthcare pre-diagnosis, access to treatment and ongoing HIV care and experiences in living with HIV yielded comparable results.

Table 4 Experiences in living with HIV among Dutch aMASE-study participants ( $n=247)$, 2013-2015

\begin{tabular}{|c|c|c|c|c|c|c|c|c|c|c|c|c|}
\hline & \multirow{2}{*}{\multicolumn{2}{|c|}{$\begin{array}{l}\text { Total } \\
(n=247)\end{array}$}} & \multirow{2}{*}{\multicolumn{2}{|c|}{$\begin{array}{l}\text { Migrant } \\
\text { MSM } \\
(n=77)\end{array}$}} & \multirow{2}{*}{\multicolumn{2}{|c|}{$\begin{array}{l}\text { Non-migrant } \\
\text { MSM } \\
(n=115)\end{array}$}} & \multirow{2}{*}{\multicolumn{2}{|c|}{$\begin{array}{l}\text { Migrant } \\
\text { heterosexual men } \\
(n=21)\end{array}$}} & \multirow{2}{*}{\multicolumn{2}{|c|}{$\begin{array}{l}\text { Non-migrant } \\
\text { heterosexual men } \\
(n=14)\end{array}$}} & \multirow{2}{*}{\multicolumn{2}{|c|}{$\begin{array}{l}\text { Migrant } \\
\text { women } \\
(n=20)\end{array}$}} \\
\hline & & & & & & & & & & & & \\
\hline & $\mathrm{n}$ & $\%$ & $n$ & $\%$ & $n$ & $\%$ & $n$ & $\%$ & $n$ & $\%$ & $n$ & $\%$ \\
\hline Disclosure of HIV status to steady partner ${ }^{a}$ & $118 / 126$ & 93.7 & $32 / 36$ & 88.9 & $60 / 62$ & 96.8 & $9 / 10$ & 90.0 & $8 / 8$ & 100.0 & $9 / 10$ & 90.0 \\
\hline Disclosure of HIV status to friends or family & $204 / 246$ & 82.9 & $63 / 77$ & 81.8 & $97 / 115$ & 84.3 & $16 / 21$ & 76.2 & $12 / 14$ & 85.7 & $16 / 19$ & 84.2 \\
\hline In contact with any NGO's for HIV support & $56 / 246$ & 22.7 & $14 / 77$ & 18.2 & $34 / 115$ & 29.6 & $3 / 21$ & 14.3 & $2 / 14$ & 14.3 & $3 / 20$ & 15.0 \\
\hline $\begin{array}{l}\text { Ever been discriminated in the Netherlands } \\
\text { because of HIV status }\end{array}$ & $40 / 246$ & 16.3 & $19 / 76$ & 25.0 & $10 / 115$ & 8.7 & $3 / 21$ & 14.3 & $2 / 14$ & 14.3 & $6 / 20$ & 30.0 \\
\hline $\begin{array}{l}\text { Ever been discriminated in the Netherlands } \\
\text { because of ethnicity, race or origin }\end{array}$ & $50 / 116$ & 43.1 & $30 / 76$ & 39.5 & $\mathrm{NA}$ & & $9 / 21$ & 42.9 & & NA & $11 / 19$ & 57.9 \\
\hline $\begin{array}{l}\text { Ever been discriminated in the Netherlands } \\
\text { because of sexuality }\end{array}$ & $88 / 191$ & 46.1 & $31 / 76$ & 40.8 & $57 / 115$ & 49.6 & & & & VA & 10 & \\
\hline
\end{tabular}




\section{Discussion}

This study, focusing on migrant and non-migrant persons recently diagnosed with HIV living in the Netherlands, found disparities in access to HIV prevention, testing and care and experience of HIVrelated discrimination by migrant status but also by sexual orientation.

Previous HIV testing and late-stage HIV infection diagnosis did not differ between migrant and nonmigrant MSM. However, migrant and non-migrant heterosexual participants were less likely to have had an HIV test before their HIV diagnosis and were more often diagnosed with a late-stage HIV infection than non-migrant MSM, indicating they are facing barriers in accessing HIV testing services. The finding that almost all participants visited a healthcare facility in the 2 years before HIV diagnosis but only in $40 \%$ an HIV test was discussed suggests that testing opportunities are being missed, as has been demonstrated at the European level [9]. In line with our findings, another study in the Netherlands found that HIV testing was often not discussed during GP consultations prior to HIV diagnosis [12]. These data suggest that increased provider-initiated testing, especially at the GP but also during hospital admissions, in dental or mental health facilities, is needed to increase earlier HIV diagnosis, especially among heterosexuals. Provider-initiated HIV testing in such settings is particularly important as data from the aMASE community survey showed that low risk perception is one of the main barriers to HIV testing among both heterosexual migrants and migrant MSM [8].

Our data show that the majority of migrant (90\%) and non-migrant (84\%) MSM had a negative HIV test before their HIV diagnosis. However, previous estimations of the aMASE study data showed that a considerable proportion of HIV-positive migrant MSM in Europe and the Netherlands acquired their HIV infection postmigration [10]. Therefore, improving early access to behavioural and biomedical HIV prevention interventions (i.e., pre- and post exposure prophylaxis [PEP and PrEP]) among HIV-negative migrant MSM is important. As a first step increasing awareness of biomedical interventions among migrant MSM is necessary as we show that PEP awareness was significantly lower among migrant MSM than among non-migrant MSM. The latter might be indicative for lower levels of awareness of PrEP and other HIV prevention strategies, such use of (free) condoms, which we did not measure.

In our study approximately one-fifth of all migrants experienced difficulties accessing healthcare in the Netherlands, which was significantly higher than among non-migrant MSM. Most reported difficulties were uncertainty about entitlement to healthcare and language barriers. These barriers are not specific to HIV-related healthcare services and have been described widely in other studies regarding access to healthcare among migrants [13]. Although almost all participants were registered at a GP and migrants living with HIV in the Netherlands experience less difficulties accessing healthcare than migrants in some other countries in Europe [9, 14], these structural barriers in the access to care for migrants need to be addressed. In the Netherlands, all residents (including asylum seekers and refugees) are entitled to a basic health insurance package which includes the bulk of essential healthcare (including care provided by a GP), medications and medical aids [15]. For undocumented migrants who lack the resources to pay for healthcare, systems are in place to reimburse medical costs [16]. Knowledge about these rights to care should be improved. Also, healthcare systems need to become more migrantfriendly, e.g., overcoming language and cultural barriers in service delivery, improving the culture competencies of health workers and organisations and improving health literacy (i.e., the degree to which an individual has the capacity to obtain, communicate, process, and understand basic health information and services to make appropriate health decisions) $[13,17,18]$. In order to decrease barriers for migrant communities, alternative options for HIV prevention, testing and care besides traditional healthcare settings should also be explored, for example through community outreach, expanding HIV support via NGO's for groups currently not reached, and the use of HIV self-tests [19-21]. As our data show about 75\% of heterosexual migrant visited a religious service, partnerships with and community outreach through religious services could be utilized to increase HIV testing.

In regard to access to HIV treatment and care, overall cART usage was high (86\%) and, although 14\% reported difficulties taking HIV medication on a regular basis, it was encouraging that self-reported cART adherence was high, with no significant differences between groups. However, we found that migrant heterosexual men and women more often reported missing an appointment at their HIV clinic because of travel expenses than nonmigrant MSM. This difference is most likely related to a lower socioeconomic status and these results are consistent with European data [8, 9]. As missing clinical appointments might lead to suboptimal HIV care and treatment, efforts should be made to discuss the costs of travel with HIV-positive patients not showing up for their appointments and opportunities to overcome such barriers should be explored. Furthermore, we found a high proportion of migrant heterosexual men and migrant women were earning less than minimum wage and experienced moderate/severe household hunger. The potential impact of poverty in this group on access to care and quality of life should be further explored.

Furthermore, our study shows that about a quarter of migrant MSM and migrant women had experienced 
HIV discrimination in the Netherlands. Previous studies have shown that HIV stigma and related HIV discrimination is a major barrier to accessing prevention, care, and treatment services and can negatively impact social relationships, the psychological wellbeing of people living with HIV/AIDS and labour participation [22-28]. As we did not ask participants about the context of HIV discrimination, it is unclear if discrimination took place at the structural, individual or community level [22, 27]. As showed that the psychological impact of stigma varies by social setting [26] and interventions to tackle HIV discrimination differ per setting [27], collecting data regarding the setting in which HIV discrimination took place in future studies is important in order to develop effective interventions. We also observed high levels of ethnic discrimination among migrants (43\%) and, among MSM, high levels of discrimination due to sexuality (46\%). These proportions are worrisome and interventions are urgently needed to limit the potential impact on quality of life and access to care.

The main strength of our study is the comparison of a rich set of data between HIV-positive migrants and nonmigrants living in the same country, data not available in many studies evaluating access to services among migrants $[8,9]$. However, some limitations need to be addressed beside the limitations of the aMASE study described elsewere [7,9]. First, due to low numbers, non-migrant women were not included in our analyses and therefore we were not able to compare outcomes between migrant and non-migrant women. Second, in our additional analyses we only corrected for age and not for socio-economic characteristics such as educational and income level. The small numbers in our study limited us to perform multivariable analyses in which variables other than age were included. Additionally, variables on socio-economic status were highly collinear with migrant status, making it difficult to tease apart the independent association of migrant status on the various outcomes with respect to socio-economic status. Third, although the survey was comprehensive, detailed information to assess determinants of underlying barriers that limit access to HIV related health services was not possible. Fourth, our results might not be generalizable to other countries/settings as they might serve different populations and migrant groups, and have different health systems. Also, the response rate of a study might affect the generalizability. The response rate in our study was $60 \%$, which is relatively high for a study covering sensitive topics such as HIV, sexuality and discrimination and focussing on migrants. However, there might be selection bias as non-respondent analyses showed that migrants from Latin America/Caribbean and women and heterosexual men were less likely to participate.

\section{Conclusions}

In conclusion, we observed disparities in access to and use of HIV-related health services and experiences in living with HIV by migrant status but also by sexual orientation. To make services more accessible and to ensure timely HIV prevention, diagnosis and care, interventions need to be tailored according to the individual. Our data suggests heterosexual men and women may particularly benefit from improved access to HIV testing (e.g. through provider-initiated testing), while migrant MSM may benefit from improved access to HIV prevention interventions (e.g., PrEP).

\section{Abbreviations}

AIDS: Acquired immunodeficiency syndrome; aMASE study: Advancing Migrant Access to health Services in Europe Study; ATHENA HIV cohort database: AIDS Therapy Evaluation in the Netherlands HIV cohort database; CART: Combination antiretroviral therapy; HIV: Human immunodeficiency virus; IQR: Interquartile range; MSM: Men who have sex with men; NGO: Nongovernmental organization; OR: Odds ratio; PEP: Post-exposure prophylaxis; PrEP: Pre-exposure prophylaxis

\section{Acknowledgements}

The authors acknowledge all participants of the aMASE study for their contribution; participating HIV treatment centers (Amsterdam UMC [location AMC], OLVG and Haaglanden Medisch Centrum), Saskia Bogers, Emilia Ric-Doe and Darshni Jhagroe for their help with the recruitment of participants during their research internship at the department of Infectious Diseases Research and Prevention of the Public Health Service of Amsterdam; the ATHENA/SHM Cohort Study for providing participants' HIV clinic data; Anders Boyd for statistical advice and the funders for the financial support.

This study would not be possible without the entire Work Package 14 collaboration. The aMASE study team are: Aerssens A, Aguado M, Alimi B, Álvarez. D, Anagnostou O, Anderson J, Antoniadou A, Arando M, Barberà MJ, Barros H, Barthélemy A, Belda-lbáñez J, Bertisch B, Bil J, Blanco JR, Block K, Boesecke C, Boura M, Burgos J, Burns FM, Cabo J, Calabuig E, Campbell L, Cardoso O, Claudia W, Clumeck N, Colucci A, Corrao S, Cuellar S, Cunha J, Daikos G, Darling K, del Amo J, del Romero J, Dellot P, Dixneuf M, Domingo P, Dronda F, Ebeling F, Engelhardt A, Engler B, Fakoya I, Farrell J, Fehr J, Feijó M, Fernández E, Fernández García E, Fernandez T, Fortes AL, Fox J, Garcia de Olalla P, García F, Gargalianos-Kakolyris P, Gennotte AF, Germano I, Gilleran G, Gilson R, Goepel S, Gogos HA, Gómez Sirvent JL, Gountas I, Gregg A, Gutiérrez F, Gutierrez MM, Hermans I, Hoeksma K, Iribarren JA, Knobel H, Koulai L, Kourkounti S, La Morté C, LeCompte T, Ledergerber B, Leonidou L, Leyten E, Ligero MC, Lindergard G, Lino S, Lopes MJ, Lopez Lirola A, Louhenapessy M, Lourida G, Luzi AM, Maltez F, Manirankunda L, Martín-Pérez A, Martins L, Masía M, Mateu MG, Meireles P, Mendes A, Metallidis S, Mguni S, Milinkovic A, Miró JM, Mohrmann K, Monge S, Montero M, Mouhebati T, Moutschen M, Müller M, Murphy C, Nöstlinger C, Ocaña I, Okumu-Fransche S, Onwuchekwa G, Ospina JE, Otiko D, Pacheco P, Palacios R, Paparizos V, Papastamopoulos V, Paredes V, Patel N, Pellicer T, Peña A, Petrosillo N, Pinheiro A, Poças J, Portillo A, Post F, Prestileo F, Prestileo T, Prins M, Prins J, Protopapas K, Psichogiou M, Pulido F, Rebollo J, Reiss P, Ribeirinho A, Río I, Robau M, Rockstroh JK, Rodrigues E, Rodríguez M, Sajani C, Salavert M, Salman R, Sanz N, Schuettfort G, Schüttfort G, Schwarze- Zander C, Serrão R, Silva D, Silva V, Silverio P, Skoutelis A, Staehelin C, Stephan C, Stretton C, Styles F, Sutre AF, Taylor S, Teixeira B, Thierfelder C, Touloumi G,

Tsachouridou O, Tudor K, Valadas E, van Frankenhuijsen M, Vázquez M, Velasco Arribas M, Vera M, Vinciana P, Volny-Anne A, Voudouri N, Wasmuth JC, Wengenroth C, Wilkins E, Young L, Yurdakul S, Zafra Espinosa T, Zuilhof W, Zuure F.

\section{Authors' contributions}

JPB interpreted the data, and wrote the draft manuscript. JPB, FRZ and MP designed this study in the Netherlands, and FRZ and MP supervised the analyses and interpretation of the data. FB led the design and implementation of the European aMASE study. DA-dA coordinated the 
European aMASE study. JMP, KB, EL were the responsible investigators in the three participating HIV outpatient clinics in the Netherlands. AvS provided clinic indicator data from the HIV ATHENA (AIDS Therapy Evaluation in the Netherlands) HIV cohort database. All authors provided substantial contributions to the interpretation of the data and to subsequent drafts and approved the final version of the manuscript.

\section{Authors' information}

Not applicable.

\section{Funding}

The aMASE study is part of Work Package 14 of EuroCoord, which is funded by the EU's Seventh Framework Programme for research, technological development, and demonstration (under grant no. 260694). Additional funding for the data collection of non-migrants and the analyses of the present study was received from the Public Health Service of Amsterdam's Research and Development Fund (project number 12-29).

The ATHENA database is maintained by Stichting HIV Monitoring and supported by a grant from the Dutch Ministry of Health, Welfare and Sport through the Centre for Infectious Disease Control of the National Institute for Public Health and the Environment.

The funders did not have involvement in study design, data collection, analysis and interpretation, nor in the writing and publication of this article.

\section{Availability of data and materials}

The data that support the findings of this study are available from the corresponding author (jbil@ggd.amsterdam.nl) and the aMASE study group but restrictions apply to the availability of these data, which were used under license for the current study, and so are not publicly available. Data are however available from the authors upon reasonable request and with permission of the aMASE study group.

\section{Ethics approval and consent to participate}

The study was submitted to the Ethics Committee of Academic Medical Center in Amsterdam who confirmed that the Medical Research Involving Human Subjects Act (WMO) does not apply to this study and therefore official approval by an Ethics Committee is not required (2013_137\#20131038). Written informed consent was obtained from all participants.

\section{Consent for publication}

Not applicable.

\section{Competing interests}

F.R. Zuure worked on projects (partly) funded or sponsored by non-restricted grants from Abbvie, Gilead Sciences, Janssen-Cilag, MSD, Orasure Technologies and Roche Diagnostics. All other authors have no conflict of interest related to this study.

\begin{abstract}
Author details
${ }^{1}$ Department of Infectious Diseases Research and Prevention, Public Health Service of Amsterdam, Amsterdam, the Netherlands. ${ }^{2}$ Amsterdam Infection and Immunity Institute (AI\&ll), Amsterdam UMC (location AMC), University of Amsterdam, Amsterdam, the Netherlands. ${ }^{3}$ Department of Internal Medicine, Amsterdam UMC (location AMC), University of Amsterdam, Amsterdam, the Netherlands. ${ }^{4}$ National Centre for Epidemiology. Instituto de Salud Carlos III, Universidad Complutense de Madrid, Madrid, Spain. ${ }^{5}$ Department of Internal Medicine, OLVG, Amsterdam, the Netherlands. ${ }^{6}$ Department of Internal Medicine, Haaglanden Medisch Centrum, The Hague, The Netherlands. ${ }^{7}$ Stichting HIV Monitoring, Amsterdam, The Netherlands. Institute for Global Health, University College London, London, UK.
\end{abstract}

\section{Received: 23 July 2019 Accepted: 13 September 2019} Published online: 29 October 2019

\section{References}

1. European Centre for Disease Prevention and Control. Migrant health: Epidemiology of HIV and AIDS in migrant communities and ethnic minorities in EU/EEA countries. Stockholm: European Centre for Disease Prevention and Control; 2010.
2. European Centre for Disease Prevention and Control. HIV and migrants: Monitoring implementation of the Dublin Declaration on Partnership to Fight HIV/AIDS in Europe and Central Asia: 2017 progress report. Stockholm: European Centre for Disease Prevention and Control; 2017.

3. Hernando V, Alvarez-del Arco D, Alejos B, Monge S, Amato-Gauci AJ, Noori $T$, Pharris $A$, del Amo J. HIV infection in migrant populations in the European Union and European economic area in 2007-2012: An epidemic on the move. J Acquir Immune Defic Syndr. 2015;70(2):204-11. https://doi. org/10.1097/QAl.0000000000000717.

4. Van Sighem Al, Boender TS, Wit FWNM, Smit C, Matser A, Reiss P. Monitoring Report 2018. Human immunodeficiency virus (HIV) infection in the Netherlands. Amsterdam: Stichting HIV Monitoring; 2018.

5. Op de Coul EL, van Sighem A, Brinkman K, van Benthem BH, van der Ende ME, Geerlings S, Reiss P, Cohort ANOH. Factors associated with presenting late or with advanced HIV disease in the Netherlands, 1996-2014: Results from a national observational cohort. BMJ Open. 2016;6(1):e009688. https:// doi.org/10.1136/bmjopen-2015-009688.

6. Van Andel E, Been SK, Rokx C, van der Ende ME. Risk factors in an HIV-infected population for refraining from specialist care. AIDS Care. 2016;28(10):1255-60. https://doi.org/10.1080/09540121.2016.1168914.

7. Fakoya I, Alvarez-Del Arco D, Monge S, Copas AJ, Gennotte AF, Volny-Anne A, Gopel S, Touloumi G, Prins M, Barros H, et al. Advancing Migrant Access to Health Services in Europe (AMASE): Protocol for a cross-sectional study. JMIR Res Protoc. 2016;5(2):e74. https://doi.org/10.2196/resprot.5085.

8. Fakoya I, Alvarez-Del Arco D, Copas AJ, Teixeira B, Block K, Gennotte AF, Volny-Anne A, Bil JP, Touloumi G, Del Amo J, et al. Factors associated with access to HIV testing and primary care among migrants living in Europe: Cross-sectional survey. JMIR Public Health Surveill. 2017;3(4):e84. https://doi. org/10.2196/publichealth.7741.

9. Fakoya I, Alvarez-Del Arco D, Monge S, Copas AJ, Gennotte AF, Volny-Anne A, Wengenroth C, Touloumi G, Prins M, Barros H, et al. HIV testing history and access to treatment among migrants living with HIV in Europe. J Int AIDS Soc. 2018;21(Suppl 4):e25123. https://doi.org/10.1002/jia2.25123.

10. Alvarez-Del Arco D, Fakoya I, Thomadakis C, Pantazis N, Touloumi G, Gennotte AF, Zuure F, Barros H, Staehelin C, Gopel S, et al. High levels of post-migration HIV acquisition within nine European countries. AIDS. 2017. https://doi.org/10.1097/QAD.0000000000001571.

11. Heinze $G$, Schemper M. A solution to the problem of separation in logistic regression. Stat Med. 2002;21(16):2409-19. https://doi.org/10.1002/sim.1047.

12. Joore IK, Geerlings SE, Brinkman K, van Bergen JE, Prins JM. The importance of registration of sexual orientation and recognition of indicator conditions for an adequate HIV risk-assessment. BMC Infect Dis. 2017;17(1):178. https:// doi.org/10.1186/s12879-017-2279-y.

13. Rechel B, Mladovsky P, Ingleby D, Mackenbach JP, McKee M. Migration and health in an increasingly diverse Europe. Lancet. 2013;381(9873):1235-45. https://doi.org/10.1016/S0140-6736(12)62086-8.

14. Ndumbi P, Del Romero J, Pulido F, Velasco Arribas M, Dronda F, Blanco Ramos JR, Garcia de Olalla P, Ocana I, Belda-lbanez J, Del Amo J, et al. Barriers to health care services for migrants living with HIV in Spain. Eur J Pub Health. 2018;28(3):451-7. https://doi.org/10.1093/eurpub/ckx225.

15. Dutch Ministry of Health, Welfare and Sport: Healthcare in the Netherlands. 2016. Available from: https://www.government.nl/documents/leaflets/2016/ 02/09/healthcare-in-the-netherlands. The Hague. (Accessed 16 Aug 2018).

16. CAK regelingen: Regeling onverzekerbare vreemdelingen [Dutch]. 2018. Available at: https://www.hetcak.nl/zakelijk/regelingen/onverzekerbarevreemdelingen. Accessed 16 Aug 2018.

17. Centers for Disease Control and Prevention: Health Literacy. 2016. Available from: http://www.cdc.gov/healthliteracy/learn/. Accessed 16 Aug 2018.

18. Perazzo J, Reyes D, Webel A. A systematic review of health literacy interventions for people living with HIV. AIDS Behav. 2017;21(3):812-21. https://doi.org/10.1007/s10461-016-1329-6.

19. World Health Organization. Guidelines on HIV Self-Testing and Partner Notification: Supplement to Consolidated Guidelines on HIV Testing Services. Geneva: World Health Organization; 2016.

20. Bil JP, Prins M, Fakoya I, Volny-Anne A, Burns F, Zuure FR. Usage of purchased self-tests for HIV infections among migrants living in the UK, France and the Netherlands: A cross-sectional study. Sex Transm Infect. 2018. https://doi.org/10.1136/sextrans-2018-053583.

21. Bil JP, Prins M, Stolte IG, Dijkshoorn H, Heijman T, Snijder MB, Davidovich U, Zuure FR. Usage of purchased self-tests for HIV and sexually transmitted infections in Amsterdam, the Netherlands: Results of population-based and serial cross- 
sectional studies among the general population and sexual risk groups. BMJ Open. 2017;7(9):e016609. https://doi.org/10.1136/bmjopen-2017-016609.

22. Alvarez-del Arco D, Monge S, Azcoaga A, Rio I, Hernando V, Gonzalez C, Alejos B, Caro AM, Perez-Cachafeiro S, Ramirez-Rubio O, et al. HIV testing and counselling for migrant populations living in high-income countries: A systematic review. Eur J Pub Health. 2013;23(6):1039-45. https://doi.org/10.1093/eurpub/cks130.

23. Fakoya I, Reynolds R, Caswell G, Shiripinda I. Barriers to HIV testing for migrant black Africans in Western Europe. HIV Med. 2008;9(Suppl 2):23-5. https://doi.org/10.1111/j.1468-1293.2008.00587.x.

24. Sumari-de Boer IM, Sprangers MA, Prins JM, Nieuwkerk PT. HIV stigma and depressive symptoms are related to adherence and virological response to antiretroviral treatment among immigrant and indigenous HIV infected patients. AIDS Behav. 2012;16(6):1681-9. https://doi.org/10.1007/s10461-011-0112-y.

25. Chinouya M, Hildreth A, Goodall D, Aspinall P, Hudson A. Migrants and HIV stigma: Findings from the stigma index study (UK). Health Soc Care Community. 2017;25(1):35-42. https://doi.org/10.1111/hsc.12179.

26. Stutterheim SE, Pryor JB, Bos AE, Hoogendijk R, Muris P, Schaalma HP. HIVrelated stigma and psychological distress: The harmful effects of specific stigma manifestations in various social settings. AIDS. 2009;23(17):2353-7. https://doi.org/10.1097/QAD.0b013e3283320dce.

27. Mahajan AP, Sayles JN, Patel VA, Remien RH, Sawires SR, Ortiz DJ, Szekeres $G$, Coates TJ. Stigma in the HIV/AIDS epidemic: a review of the literature and recommendations for the way forward. AIDS. 2008;22(Suppl 2):S67-79. https://doi.org/10.1097/01.aids.0000327438.13291.62.

28. Stutterheim SE, Brands R, Baas I, Lechner L, Kok G, Bos AER. HIV status disclosure in the workplace: Positive and stigmatizing experiences of health care workers living with HIV. J Assoc Nurses AIDS Care. 2017;28(6):923-37. https://doi.org/10.1016/j.jana.2017.06.014.

\section{Publisher's Note}

Springer Nature remains neutral with regard to jurisdictional claims in published maps and institutional affiliations.

Ready to submit your research? Choose BMC and benefit from:

- fast, convenient online submission

- thorough peer review by experienced researchers in your field

- rapid publication on acceptance

- support for research data, including large and complex data types

- gold Open Access which fosters wider collaboration and increased citations

- maximum visibility for your research: over $100 \mathrm{M}$ website views per year

At $\mathrm{BMC}$, research is always in progress.

Learn more biomedcentral.com/submissions 